
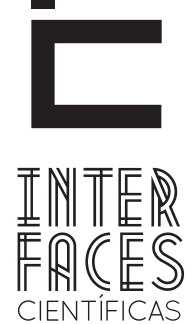

DIREITO

\title{
LIBERDADE RELIGIOSA VERSUS LIBERDADE DE EXPRESSÃO: VIOLAÇÕES AOS DIREITOS HUMANOS DOS RELIGIOSOS DE MATRIZ AFRICANA NOS MEIOS DE COMUNICAÇÃO DE MASSA NO BRASIL
}

\section{RESUMO}

O presente trabalho se propõe a discutir a tensão existente na relação entre as normas constitucionais que asseguram o exercício do direito à liberdade religiosa e do também direito fundamental à liberdade de expressão, a partir de casos judiciais que colocam em questão o direito de liberdade de expressão dos religiosos neopentecostais e similares, e o seu exercício diante do direito de liberdade religiosa das religiões de matriz africana e, como em casos concretos, por meio dos mecanismos previstos no ordenamento jurídico brasileiro, possíveis limites possam ser estabelecidos para resolver, com o uso da hermenêutica jurídica, a referida colisão de princípios sem que se configure o abuso de direito.

\section{PALAVRAS-CHAVE}

Liberdades Fundamentais. Religiões de Matriz Africana. Intolerância Religiosa. Colisão de Princípios

\section{ABSTRACT}

This paper aims to discuss the tension in the relationship between constitutional rules that guarantee the right to religious freedom and also the fundamental right to freedom of expression, from court cases that challenge the right to freedom of expression of religious neo-Pentecostal and similar, and exercise before the right to religious freedom of religions with African roots, and as in specific cases, through the mechanisms provided in the Brazilian legal system, possible limits may be established to resolve, with the use of legal hermeneutics, such a collision of principles without being configure the abuse of rights.

\section{KEYWORDS}

Fundamental Freedoms. Religions with African Roots. Religious Intolerance. Collision of Principles. 


\section{RESUMEN}

El presente trabajo se propone a discutir la tensión existente en la relación entre las normas constitucionales que aseguran el ejercicio del derecho a la libertad religiosa y del también derecho fundamental a la libertad de expresión, a partir de casos judiciales que ponen en cuestión el derecho de libertad de expresión de los religiosos neo-pentecostales y similares, y su ejercicio delante del derecho de libertad religiosa de las religiones de matriz africana y como en casos concretos, por medio de los mecanis- mos previstos en el ordenamiento jurídico brasileño, se puedan establecer posibles límites para resolver, con el uso de la hermenéutica jurídica, la referida colisión de principios sin que se configure el abuso de derecho.

\section{PALABRAS CLAVE}

Libertades Fundamentales. Religiones de Matriz Africana. Intolerancia Religiosa. Colisión de Principios.

\section{INTRODUÇÃO}

Os casos de intolerância, antes apenas episódicos e sem grandes repercussões, hoje se avolumaram e saíram da esfera das relações cotidianas menos visíveis para ganhar visibilidade pública, conforme atestam as frequentes notícias de jornais que os registram em inúmeros pontos do Brasil. Igualmente, a reação a estes casos, antes apenas um esboço isolado e tímido de algumas vítimas, agora se faz em termos de processos criminais levados adiante por pessoas físicas ou instituições públicas, como ONGs e até mesmo a Promotoria Pública (SILVA, 2007, p. 10).

Silva (2007, p. 10) sistematizou e classificou os casos de intolerância segundo os seguintes critérios: 1) ataques feitos no âmbito dos cultos das igrejas neopentecostais e em seus meios de divulgação e proselitismo; 2) agressões físicas in loco contra terreiros e seus membros; 3 ) ataques às cerimônias religiosas afro-brasileiras realizadas em locais públicos ou aos símbolos dessas religiões existentes em tais espaços; 4) ataques a outros símbolos da herança africana no Brasil que tenham alguma relação com as religiões afro-brasileiras; 5) ataques decorrentes das alianças entre igrejas e políticos evangélicos e, finalmente; 6) as reações públicas (políticas e judiciais) dos adeptos das religiões afro-brasileiras.
No presente artigo enfocaremos apenas o primeiro tipo de manifestação de violação ao direito fundamental à liberdade religiosa de matriz africana em nosso país: 1) Os ataques feitos no âmbito das práticas rituais das igrejas neopentecostais e de seus meios de divulgação e proselitismo.

Para Silva (2007, p. 10-11) essas violações têm como ponto de partida uma teologia assentada na ideia de que a causa de grande parte dos males deste mundo pode ser atribuída à presença do demônio, que geralmente é associado aos deuses de outras denominações religiosas, especialmente aos Orixás, Caboclos e Guias das religiões afro-brasileiras.

Segundo Silva (2007, p. 11), dos púlpitos das igrejas esse tipo de ataque se estende para os programas religiosos ("Fala que Eu te Escuto", "Ponto de Luz", "Pare de Sofrer", "Show da Fé" etc.) transmitidos pela Rede Record, principal rede evangélica do nosso país na atualidade, e por outras emissoras que tem seus horários comprados pelas igrejas neopentecostais. 0 autor salienta que em muitos desses programas são exibidas "reconstituições de casos reais" ou dramatizações nas quais símbolos e elementos das religiões 
afro-brasileiras são retratados como meios espirituais para a obtenção unicamente de malefícios: morte de inimigos, disseminação de doenças, separação de casais ou amarração amorosa, desavença na família etc. São comuns nesses programas os testemunhos de conversão dados por pessoas que se apresentam como antigos frequentadores de terreiros, que são entrevistados pelo pastor e "confessam" os malefícios que teriam sido feitos com ajuda das entidades afro-brasileiras (chamadas de "encostos"). Os testemunhos mais explorados são os dos que se apresentam como ex-sacerdotes das religiões afro-brasileiras, chamados de "ex-pais-de-encosto" que explicam detalhadamente como faziam os despachos e sua intenção malévola.

A vasta rede de comunicação dessas igrejas inclui ainda programas de rádio, sites na Internet e material de divulgação religiosa (livros, jornais, revistas e foIhetos), como a Folha Universal e a revista Plenitude, ambas da lurd - Igreja Universal do Reino de Deus, e os livros best-sellers Orixás, Caboclos \& Guias; Deuses ou Demônios?, do bispo Edir Macedo (lurd), e Espiritismo. A Magia do Engano, do missionário R. R. Soares (Igreja Internacional da Graça de Deus).

Diante desse quadro, o presente trabalho se propõe a discutir a tensão existente na relação entre as normas constitucionais que asseguram o exercício do direito à liberdade religiosa. E, também, do direito fundamental à liberdade de expressão e, como em casos concretos, por meio dos mecanismos previstos no ordenamento jurídico brasileiro, possíveis limites possam ser estabelecidos para resolver, com o uso da hermenêutica jurídica, a referida colisão de princípios sem que se configure o abuso de direito.
Para isso, é fundamental que seja considerado como pressuposto teórico do referido estudo o Estado Democrático de Direito, pautado na laicidade, no respeito aos direitos e às garantias constitucionais de todos, em especial, ao princípio da legalidade ao estabelecer os limites para o exercício dos direitos fundamentais, em especial, a liberdade em suas mais diversas acepções (religiosa, de expressão, sexual, dentre outras) e como norteador da valoração realizada pela comunidade jurídica ao escolher os fatos que deverão sofrer as sanções estatais.

Assim, o tema proposto se justifica por apresentar atualidade e relevância, considerando os inúmeros casos de intolerância religiosa registrados em nosso país e levados aos tribunais, especialmente os mais recentes casos de veiculação na mídia televisiva, rádio, jornais e livros, por alguns representantes de igrejas evangélicas, de manifestações e discursos atentatórios aos direitos dos religiosos afro-brasileiros.

De antemão vale frisar que o presente trabalho não tem o escopo de fornecer uma solução pronta e acabada para a situação exposta acima. No entanto, com o intuito de construir possibilidades de enfretamento ao tema serão trabalhados a seguir três eixos centrais, a saber: (1) a relação entre o Estado laico e a garantia da liberdade religiosa; (2) a mídia televisiva enquanto concessão pública e os possíveis limites à liberdade de expressão dos religiosos quando da prática de atos atentatórios aos direitos fundamentais de outros grupos religiosos; (3) a viabilidade de se judicializar estas ofensas e se criar outras formas de limitação à liberdade de expressão nos veículos de comunicação em massa para a resolução desses casos. 


\section{LIBERDADE RELIGIOSA NO ESTADO LAICO}

A convivência social é marcada por diversos processos de adaptação social que são instrumentos usados pela coletividade para agir sobre o indivíduo, influenciando-o com os valores, as concepções e os sentimentos que integram e representam a própria cultura da sociedade em que este se encontra inserido. Dentre os referidos processos, destaque-se que o Direito é uma das principais formas de controle social e de resolução de conflitos do homem em suas relações intersubjetivas.

Vale ressaltar que, historicamente, seja numa perspectiva teórica, seja numa perspectiva prática, pode-se afirmar que a sociedade humana não pode prescindir dos instrumentos de adaptação social, especialmente o direito. Diante dessa realidade, atente-se para o fato do direito pertencer ao gênero dos complexos normativos que regulam as ações livres (dependentes da vontade) dos homens. Em decorrência disso, uma das questões fundamentais reside na diferença específica do direito em relação às outras ordens normativas que também regulam estas ações (religião, moral, bons costumes, boa educação).

É comum a opinião de que a diferença específica reside na coercibilidade estadual das normas jurídicas. Esta opinião liga indissociavelmente Direito e Estado e, por isso, é característica das concepções legalistas do direito, marcadas por limitações e irrealismo. Mas há mais. Será, realmente, que basta que o Estado ameace, com uma sanção, quem violar uma norma, para que, por esta simples característica externa (ou formal), essa norma se torne numa norma jurídica? Por outras palavras: não haverá nada de substancial, de interno - como, por exemplo, uma certa fonte de legitimidade (gerando uma razão específica para obedecer), a referência a um certo valor a proteger (a uma certa finalidade a prosseguir), distinto dos outros, protegidos (ou prosseguidos) por outras ordens normativas -, no conceito de direito? E será que, por outro lado, tudo o que estiver privado dessa estampilha estadual está, irremediavelmente, fora do direito? Perguntar isto significa, nomeadamente, questionar se o direito não se distingue por estar ao serviço (por ter como função assegurar a realização) de certos valores específicos (digamos, a justiça deste mundo, a ordem da cidade), seja ele formulado por quem for (HESPANHA, 2009, p.81).

Independentemente das conclusões que se chegue como consequência das questões acima levantadas, tem-se como marco distintivo dos Estados Modernos que emergiram a partir da derrocada do Estado Absolutista, o primado da legalidade como o princípio estruturante do Estado de Direito na

\begin{abstract}
convicção de que todos os seres humanos têm direito a ser igualmente respeitados, pelo simples fato de sua humanidade, nasce vinculada a uma instituição social de capital importância: a lei escrita, como regra geral e uniforme, igualmente aplicável a todos os indivíduos que vivem numa sociedade organizada (COMPARATO, 2008, p. 12).
\end{abstract}

Por conseguinte, a tutela constitucional de proteção dos direitos fundamentais pelo ordenamento jurídico brasileiro deve pautar-se na universalidade, na aplicação imediata e na garantia do valor dignidade da pessoa humana para todos os indivíduos independentemente de quaisquer formas de discriminação (racial, étnica, de gênero, sexual, religiosa, dentre outras).

Dentro do escopo do presente trabalho, cabe anotar que, no mundo ocidental, o desenvolvimento da ideia de tolerância religiosa e, posteriormente, de liberdade religiosa, bem como a separação entre Igreja e Estado, ocorreu de forma lenta e gradual com a transição do Estado moderno e monárquico para o Estado constitucional e republicano. E, em decorrência disso, teve-se a constitucionalização do direito fundamental de liberdade religiosa e da laicidade do Estado. 
Além disso, destaque para a contribuição dada pelo sistema global de proteção aos direitos humanos, conforme previsão da garantia da liberdade religiosa como direito de toda pessoa no art. 18, da Declaração Universal dos Direitos do Homem, da Organização das Nações Unidas (ONU), de 10 de dezembro de 1948; e no art. 18 do Pacto Internacional sobre Direitos Civis e Políticos, também da ONU, de 16 de dezembro de 1966. Da mesma forma que também o fez o sistema regional interamericano de proteção de direitos humanos, no art. 12, da Convenção Americana de Direitos Humanos - Pacto de San José da Costa Rica, de 1969.

A Constituição Federal do Brasil de 1988, em seu art. $5^{\circ}$, VI, prevê que é inviolável a liberdade de consciência e de crença, sendo assegurado o livre exercício dos cultos religiosos e garantida, na forma da lei, a proteção aos locais de culto e suas liturgias. Assim,

a Constituição protege todas as crenças, consagrando uma era de profundo respeito à liberdade religiosa. Manteve a separação entre o Estado e a Igreja, situação inaugurada pela Constituição de 1891, porém estabelecendo um regime de colaboração entre eles, de interesse público. Conforme o art. 19, I, é vedado à União, aos Estados, ao Distrito Federal e aos Municípios estabelecer cultos religiosos ou igrejas, subvencioná-los, embaraçar-lhes o funcionamento ou manter com eles ou seus representantes relações de dependência ou aliança, ressalvada, na forma da lei, a colaboração de interesse público. Não se adotou, portanto, uma religião oficial, como ocorreu na Carta do Império de 1824. Consagrou um Estado laico, não confessional (CUNHA JÚNIOR, 2008, p. 655).

Dessa maneira, a separação orgânica e formal entre a Igreja e o Estado foi fator histórico decisivo para o surgimento e a nova identidade do Estado nacional. Assim se justifica a adoção da laicidade como característica do Estado em toda sociedade que deseja harmonizar relações sociais marcadas por interesses e concepções morais ou religiosas plurais. Além disso, a possibilidade do alcance de uma convivência social que respeite a diversidade de pensamento é maior com o fortalecimento das liberdades.

\begin{abstract}
O princípio da laicidade [...] é principalmente um princípio constitutivo do Estado de Direito moderno que se projeta sobre todos os ramos do Direito e todas as políticas públicas do Estado. Portanto, não é somente um princípio que define a formulação da política religiosa dos Estados democráticos, mas sim, um princípio constitucional, que também informa o conjunto do ordenamento jurídico e as políticas públicas em geral (HUACO, 2008, p. 41).
\end{abstract}

Nesse sentido, a Declaração universal da laicidade no século $X X I^{1}$ destaca em seu preâmbulo que os Estados devem buscar o equilíbrio entre os princípios essenciais que favoreçam o respeito pela diversidade e a integração de todos os cidadãos com a esfera pública. Isso implica também o respeito pelo Estado, dentro dos limites de uma ordem pública democrática e da observância aos direitos fundamentais, à autonomia das religiões e das convicções religiosas. Em seu artigo 4, a laicidade é definida como princípio fundamental do Estado de Direito, in verbis:

\footnotetext{
Artigo 4. Definimos a laicidade como a harmonização, em diversas conjunturas sócio-históricas e geopolíticas, dos três princípios já indicados: respeito à liberdade de consciência e à sua prática individual e coletiva; autonomia da política e da sociedade civil com relação às normas religiosas e filosóficas particulares; nenhuma discriminação direta ou indireta contra os seres humanos (LOREA, 2008, p. 8)
}

Vale o registro de que a laicidade não significa abolir a religião, pelo contrário ela se configura na liberdade de decisão individual de decisão em matéria de religião assegurando assim uma articulação da diversidade cultural e da unidade política e social dos integrantes de uma sociedade pautada na democracia e no pluralismo de idéias, crenças e pensamentos. 


\section{LIBERDADE DE EXPRESSÃO E RELIGIOSA NA MÍDIA TELEVISIVA: PRÁTICAS E DISCURSOS ATENTATÓRIOS AOS DIREITOS HUMANOS DAS RELIGIÕES DE MATRIZ AFRICANA}

Apesar de se reconhecer que em nenhum país e em nenhuma sociedade existe uma laicidade absoluta e que tampouco as diversas soluções disponíveis em matéria de laicidade são equivalentes. Na realidade ocidental e, mais notadamente, no Brasil, ainda parece não se ter solidificado por completo a ideia da liberdade religiosa como elemento necessário para a sobrevivência de uma sociedade pluralista (COSTA, 2008, p. 114).

Conforme já sinalizado nas considerações iniciais do presente trabalho, tal cenário é evidenciado na conduta deliberada de parte do segmento evangélico ao fazer uso da concessão pública de mídia televisiva para disseminar, em nome da liberdade religiosa, discursos de ódio pautados na ofensa gratuita aos Templos religiosos afro-brasileiros e aos seus seguidores, por meio de espetáculos midiáticos que reiteram a intolerância, a estigmatização, o preconceito e a discriminação.

Como resultado desses atos, temos em nosso país dois casos emblemáticos: 1) a Ação civil pública proposta pelo Ministério Público Federal da Bahia para proibir a venda em todo o Brasil do livro "Orixás, Caboclos e Guias Deuses ou Demônios?”, escrito pelo bispo Edir Macedo, um dos fundadores da Igreja Universal do Reino de Deus. Movida pelos procuradores Sidney Madruga e Cláudio Gusmão, a ação sustentou que a obra é degradante, injuriosa, preconceituosa e discriminatória em relação às religiões afros - candomblé, umbanda e quimbanda; e 2) a Ação civil pública proposta pelo Ministério Público Federal de São Paulo contra a Rede Record e a TV Gazeta pedindo indenização pela discriminação das religiões de origem afro-brasileira na programação das emissoras.
Estes são dois exemplos de situações concretas em que se caracteriza a tensão entre liberdades (religiosa e de expressão), da qual se origina diferentes interpretações do que é justo e adequado no que se refere ao pertencimento religioso e à manutenção de um espaço público democrático que assegure a liberdade de consciência e a diversidade de pensamento. Diante disso, cabe ressaltar que, por força do dispositivo constitucional do art. $3^{\circ}$, IV, da Constituição Federal de 1988, a diversidade religiosa possui a garantia de livre exercício de suas respectivas identidades sexuais. E, consequentemente, infere-se que, ao se pautar no pluralismo, no multiculturalismo e em instituições políticas legitimadas pela soberania popular e já não mais por elementos religiosos, o Estado laico protege melhor as minorias.

\begin{abstract}
O Estado laico é em sua essência um instrumento jurídico-político para a gestão das liberdades e direitos do conjunto de cidadãos. Nesse sentido, alguns direitos de reivindicação recente, como os sexuais e reprodutivos, estão ligados intrinsecamente ao referido Estado por diversas razões. A principal é pela obrigação do Estado moderno de preservar a liberdade de consciência frente a qualquer ameaça que atente contra sua liberdade. [...] 0 respeito à liberdade de consciência e a inevitável pluralidade de crenças tem levado à formação de um espaço público secularizado (recordemos do registro de nascimento e do matrimônio civil), a princípio, alheio à influência das doutrinas religiosas e baseado na moral pública decidida por vontade popular em função do interesse público. [...] Evidentemente, a moral pública não pode estar totalmente secularizada, à medida que as religiões formam parte essencial da cultura dos povos, portanto, é impossível que não influenciem em suas concepções morais sobre o que é correto ou incorreto, sobre o que é bom ou mau (BLANCARTE, 2008, p. 26-27).
\end{abstract}

Todavia, saliente-se que, apesar de possuírem suas crenças pessoais, os legisladores e funcionários 
públicos não devem nem podem impô-las à população devendo primar pelo interesse público em suas funções e responsabilidades. Esse entendimento deve ser também adotado quando o agente exerce sua liberdade de expressão em um meio de comunicação de massa através de concessão pública. Tal exigência se dá pela necessidade de harmonia entre os direitos individuais, uma vez que a fundamentabilidade da liberdade de expressão não é absoluta e, em qualquer momento, expressões sem limites podem entrar em conflito com interesses públicos e privados relevantes (TAVARES, 2007, p. 240).

0 que vem a ratificar que os direitos religiosos, mais além de sua existência natural, podem ser reconhecidos, defendidos e garantidos, na medida em que a vontade popular, ou os magistrados e tribunais superiores de justiça, assim o decidirem. Assim, considerados os pressupostos teóricos do Estado Democrático de Direito, um dos maiores riscos da democracia moderna é confundir liderança religiosa com liderança política, especialmente, no exercício do direito à liberdade de expressão e religiosa na televisão. Dessa forma,

um determinado ato somente poderá ser considerado como concretização da liberdade de expressão se não ultrapassar o limite imposto pelo conceito de liberdade, qual seja, o respeito (responsabilidade) que deve haver no uso da liberdade. Conforme se verificará mais adiante, a liberdade de expressão implica a necessidade de harmonização e consideração dos demais direitos sob o risco de perder a característica liberdade e, por conseguinte, passar a ser uma "arbitrariedade" de expressão (TAVARES, 2008, p. 232).

É inadmissível que religiosos através da mídia televisiva se respaldem no direito de liberdade de expressão para amparar discurso de ódio, que não condiz com as funções constitucionais da comunicação social. No entanto, os religiosos têm todo o direito de exigir em seus templos determinado comportamento de seus fiéis, que são livres, felizmente - ao menos é assim nas culturas não teocráticas -, para escolherem o seu caminho. Se uma determinada religião os oprime, podem escolher outra.
Em outras palavras, ainda que a crença religiosa não se coadune com a prática de outras religiões, incitar a violência ou o desrespeito extrapola os direitos de livre expressão e viola a laicidade do Estado e os direitos fundamentais das minorias religiosas. Além disso, as emissoras de televisão são concessionárias do serviço público federal de radiodifusão e deve compatibilizar sua atuação com preceitos fundamentais como o direito à honra e a não discriminação.

O desafio que se impõe para a deliberação dessa colisão de valores e a concretização do interesse público é o estabelecimento de uma relação equilibrada na ubiquidade existente entre democracia deliberativa e jurisdição constitucional. Preliminarmente, cabe salientar que um Estado republicano deve ter como postulado a liberdade e a igualdade de todas as pessoas e, por conseguinte, o dever de igual consideração e respeito que a comunidade, atuando coletivamente, e seus indivíduos devem a cada uma das pessoas humanas que nela vivem. Por isso,

\begin{abstract}
a característica mais importante do Estado Democrático de Direito consiste justamente nessa migração de conteúdos morais da esfera do político para a esfera do jurídico, movimento que implica e exige a afirmação do Poder Judiciário como mecanismo de garantia institucional dos conteúdos constitucionalizados (MELLO, 2004, p.183).
\end{abstract}

Evitando com isso que, através do exercício da democracia, tenha-se uma exacerbação da vontade da maioria sobre princípio da tolerância e o direito de ser diferente, configurando uma ditadura das multidões e legitimando violações aos direitos fundamentais das minorias com a imposição de crenças, valores e pensamentos. Por isso, o exercício da jurisdição constitucional, enquanto guardião da constituição e do equilíbrio entre os direitos fundamentais e a soberania popular, inclusive com decisões contramajoritárias apoiadas nos princípios da hermenêutica constitucional, é compatível com democracia deliberativa e fator decisivo para a legitimidade e eficiência do regime democrático. 
Diante disso, como o Estado deve assegurar a efetividade dos direitos fundamentais colidentes de liberdade religiosa, de liberdade de expressão e outras, sem caracterizar abuso de direito? Assim, a solução hermenêutica para as colisões de princípios se dá através da utilização da técnica da ponderação, com a aplicação dos postulados da proporcionalidade e da razoabilidade. A ponderação estabelece uma "relação de precedência condicionada" entre os princípios em conflito. Ou seja, a aplicação do princípio ao caso concreto depende das condições fáticas subjacentes. Dadas determinadas condições, o resultado será um. Se essas condições forem diversas, o resultado poderá ser diferente. Nesse contexto, é comum afirmar-se que não há relação hierárquica entre os princípios salvaguardados pela Constituição (KOATZ, 2011, p. 401).

Para o enfrentamento do abuso de direito, o próprio texto constitucional, baseado no princípio da tolerância e da não discriminação, legitima a implementação de restrições legais, civis e criminais, que visem conter ou limitar as condutas expressivas que tenham por único objetivo a ofensa e a humilhação social de determinados grupos sociais, inclusive para os casos de intolerância religiosa.

\section{CONCLUSÃO}

Adotando como premissa que a legalidade e a laicidade do Estado de Direito não podem ser afastadas diante de contingências políticas ou do clamor social, o respeito aos princípios fundamentais constitucionais deve ser resguardado com toda a firmeza, mesmo diante dos mais intensos brados pela implantação de fundamentalismo militante religioso e pela estigmatização irracional das minorias sexuais a qualquer custo.

Além disso, o princípio da tolerância que assegura o direito à diferença e à diversidade impõe a necessidade de se realizar a ponderação de interesses cons-
Para Weingartner Neto (2007, p. 309), estes limites devem balizar o "discurso do ódio" e as "palavras de guerra", na medida em que a comunicação de tais conteúdos provoca um dano de status (ou lesão estigmática) num determinado grupo e por essa via, nos seus membros individualmente considerados - o que se acentua especialmente quando sua identidade, numa parte substancial, é definida pelo seu sexo ou orientação, raça, religião.

\begin{abstract}
De uma maneira geral, como é notoriamente conhecido, o emissor-mídia encontra-se preocupado, invariavelmente, com seu grau de penetração, com o aumento de sua audiência. Daí a especial necessidade de se criarem freios e de parâmetros qualitativos serem impostos ao exercício do direito de comunicação. [Além disso,] apesar de cada indivíduo (tomado como audiência) poder se recusar a aceitar aquilo que the é impingido pelo emissor-comunicador, seu controle e suas reservas muitas vezes não são suficientes, não deixando de ser influenciado e "modificado" pelo que viu ou ouviu em função do exercício da liberdade de expressão por outrem, especialmente por um emissor-comunicador (TAVARES, 2007, p. 241-242).
\end{abstract}

É sob esse cenário que se insere o art. $5^{\circ}, \mathrm{XLI}$, da Constituição Federal, in verbis: "a lei punirá qualquer discriminação atentatória dos direitos e liberdades fundamentais" e na vedação de quaisquer formas de discriminação, conforme o art. $3^{\circ}$, IV, da Carta Magna.

titucionais colidentes, através da proporcionalidade e da razoabilidade, para enfrentar qualquer tipo de discriminação, especialmente, quando do uso do espaço público, como é o caso de determinados setores evangélicos que possuem concessão pública na mídia televisa.

Diante disso, na análise de casos concretos, é possível o estabelecimento de limites para resolver hermeneuticamente a referida colisão de princípios sem que se configure o abuso de direito. Nesse trabalho, sugere-se que tal controle do abuso de direito 
da liberdade de expressão e religiosa seja exercido em esferas do direito, tais como a administrativa e a cível. No entanto, vale ressaltar que isso não quer dizer o retorno da censura, mas a afirmação do respeito à

\section{REFERÊNCIAS}

ALMEIDA, Ronaldo. 0 que significa o crescimento evangélico no Brasil? In: Le Monde Diplomatique Brasil. Ano 5, n. 52, Novembro, 2011, p.18-19.

ANDRADE, Vera Regina Pereira de. A ilusão de segurança jurídica: do controle da violência à violência do controle penal. 2. ed. Porto Alegre: Livraria do Advogado, 2003.

BLANCARTE, Roberto. O porquê de um Estado laico. In: LOREA, Roberto Arriada (org.). Em Defesa das Liberdades Laicas. Porto Alegre: Livraria do Advogado, 2008, p. 19-32.

CAMARGO, Marcelo Novelino (org.). Leituras Complementares de Constitucional: Direitos Fundamentais. 2. ed. Salvador: JusPodivm, 2007.

CAMPOS, Marcelo da Silveira. Crime e Congresso Nacional: Uma análise da política criminal aprovada de 1989 a 2006. São Paulo: IBCCRIM, 2010.

COMPARATO, Fábio Konder. A afirmação histórica dos direitos humanos. 6. ed. São Paulo: Saraiva, 2008.

COSTA, Maria Emília Corrêa da. Apontamentos sobre a liberdade religiosa e a formação do Estado Laico. In: LOREA, Roberto Arriada (org.). Em Defesa das Liberdades Laicas. Porto Alegre: Livraria do Advogado, 2008, p. 97-116.

CUNHA JÚNIOR, Dirley. Curso de Direito Constitucional. 2. ed. Salvador: JusPodivm, 2008. diversidade religiosa, o fortalecimento da laicidade, a garantia plena do direito fundamental de liberdade religiosa como pilares para a real formação de uma sociedade pluralista e democrática.

HESPANHA, António Manuel. 0 Caleidoscópio do Direito: o direito e a justiça nos dias e no mundo de hoje. 2. ed. Coimbra: Almedina, 2009.

HUACO, Marco. A laicidade como princípio constitucional do Estado de Direito. In: LOREA, Roberto Arriada (org.). Em Defesa das Liberdades Laicas. Porto Alegre: Livraria do Advogado, 2008, p. 33-80.

KOATZ, Rafael Lorenzo-Fernandez. As Liberdades de Expressão e de Imprensa na Jurisprudência do STF. In: SARMENTO, Daniel; SARLET, Ingo Wolfgang (orgs.). Direitos Fundamentais no Supremo Tribunal Federal: Balanço e Crítica. Rio de Janeiro: Lúmen Júris, 2011.

LOREA, Roberto Arriada (org.). Em Defesa das Liberdades Laicas. Porto Alegre: Livraria do Advogado, 2008.

MARTIN, Luis Gracia. Prolegômenos para a Luta pela Modernização e Expansão do Direito Penal e para a Crítica do Discurso de Resistência. Porto Alegre: Sérgio Antonio Fabris Editor, 2005.

MELLO, Cláudio Ari. Democracia Constitucional e Direitos Fundamentais. Porto Alegre: Livraria do Advogado, 2004.

SARMENTO, Daniel; SARLET, Ingo Wolfgang (orgs.). Direitos Fundamentais no Supremo Tribunal Federal: Balanço e Crítica. Rio de Janeiro: Lúmen Júris, 2011. 
SILVA, Vagner Gonçalves da. Intolerância religiosa Impactos do Neopentecostalismo no campo religioso afro-brasileiro. São Paulo: Editora da Universidade de São Paulo, 2007. 328 p.

TAVARES, André Ramos. Liberdade de Expressão-Comunicação, Limitações quanto ao seu Exercício e Possibilidade de Regulamentação. In: CAMARGO, Marcelo Novelino (org.). Leituras complementares de Constitucional: Direitos Fundamentais. 2. ed. Salvador: JusPodivm, 2007.

I Doutorando em Direito pela Pontifícia Universidade Católica do Rio de Janeiro - PUC/RIO, Mestre em Direito pela Universidade Federal da Bahia e professor de Direito Constitucional.Email: ilzver_matos@unit.br

II Mestrando em Direito pela Universidade Federal de Alagoas. Professor da Universidade Tiradentes e da Faculdade Pio Décimo. Email: rcjalves@uol.com.br

Recebido em: 20 dezembro de 2012

Data da avaliação: 22 de janeiro de 2013

Data de aceite: 26 de janeiro de 2013
WEINGARTNER NETO, Jayme. Liberdade religiosa na Constituição: Fundamentalismo, Pluralismo, Crenças, Cultos. Porto Alegre: Livraria do Advogado, 2007.
1 Declaração apresentada no Senado francês, em 09 de dezembro de 2005, por ocasião das comemorações do centenário da separação Estado-Igrejas na França; cuja redação esteve a cargo de Jean Baubérot (França), Micheline Milot (Canadá) e Roberto Blancarte (México). 